\title{
INFLUENCE OF MAGNETIC FIELD UPON THE WEAR OF STEEL/STEEL AND BRASS/STEEL COMBINATIONS UNDER DRY AND LUBRICATED CONDITIONS
}

$$
\begin{aligned}
& \text { تأثيز المجال المغناطيسى على تآكل مجموعات من الصطب/ملب ر نحاس/ مسلب }
\end{aligned}
$$

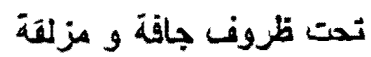

$$
\begin{aligned}
& \text { M. ZAKI }
\end{aligned}
$$

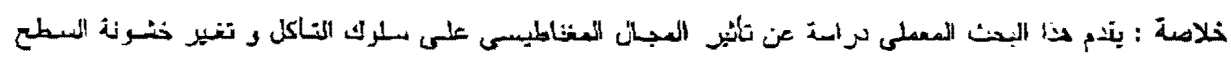

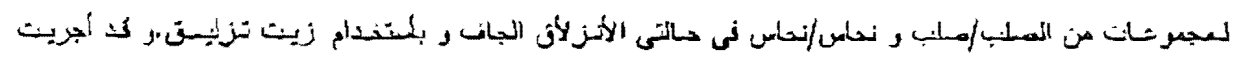

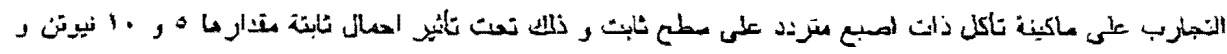

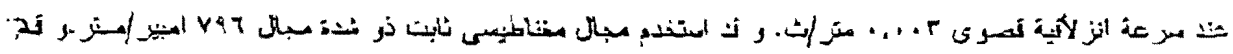

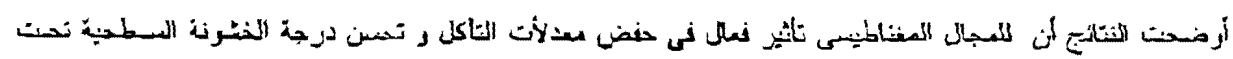

$$
\begin{aligned}
& \text { ظلرون الثتنيل المختبرة. }
\end{aligned}
$$

ABSTRACT: An experimental investigation was carried out to elucidnte the role of magnetic field on the wear behavior and surface roughness variations of steel/steci and brass/stcel combinations under dry and oil lubricated sliding conditions. A reciprocaling pin-an-plate wear testing nlachine was used wilh normal loads of either $5 \mathrm{~N}$ or $10 \mathrm{~N}$ and with naximum sliding speed of $0.03 \mathrm{w}$ s. A constint magnetic fieid strength of $796 \mathrm{~A} / \mathrm{in}$ was applied to the mubbing surfaces during tests conducted in the presence of magnetic field. The resulis of the experiments show that the presence of magnetic field has a significamt effect upon reducing wear rates of both tested combinations of materials under dry and lubricated sliding condicions. Furthermore, an improvement in counterfnce surface roughness was obsencd ind mensured due to the presence of inagnetic field between sliding surfaces.

\section{INTRODUCTION}

During rubbing of metals, continuous changes in the energy of atomic and molecular interactions of surfaces take place. A whole complex of interconnected mechanical, physicochemical and electrical phenomena are encountered [1]. These phenomena can influence both the force of interaction between atoms and atomic collections and the very character of bonds In addition, these phenomena continually disturb the conditions of the system, either in dry or lubricated sliding. This sort of disturbance sesults in changes in the macroscopic mechanical and physical parameters: friction force, wear rate, surface roughness, surface hardness...etc. Therefore, it is evident that great applied value is attached to the study of specific features of the electrical and magnetic influences upon friction and wear of metals. The study should aim to decrease friction, wear resistance to plastic strains and work to overcome molecular forces in the formation of new surfaces.

It is important to mention that in the devising of new friction and wear theories, the resent emphasis is not on the inechanical models of interaction of solids but on the little studied category of electric and electromagneric processes taking place between sliding surfaces, which influences the friction and wear[2-3].

For tribological systems, the principles of magnetism can be used for the separation of the surfaces in relative motion in two ways: The first is to utilize the effect of a load-carrying 
force generated by the flow of conducting fluid within a magnetic field causing magnetohydrodynamic (MHD) lubrication [4].The second in case of no lubricant, the systems derive their load-carrying ability from the attraction and repulsion associated with the magnetic fields, as in magnetic suspension bearings [5]. It is known from the laws of electromagnetic that an electric charge $(\mathrm{q})$ moving with a velocity $(\mathrm{v})$ within a magnetic field (B) will experience a force (F) called Lorentz force, acting perpendicular to the direction of motion according to the equation :

$$
F=q(\vee \times B)
$$

It follows that for MHD lubrication, the conducting fluid will develop a pressure which can exceed the ordinary hydrodynamically generated pressure [8], capable of reducing friction and wear of sliding metal surfaces. Some investigators [6] have found that it is possible to control wear in ionically conducting fluid through the application of appropriate electrochemical potentials. They concluded that the wear of $\mathrm{Ni}(200)$ reduced by a factor of 10 over the wear at the open-circuit potential. Hiratsuka et al [7] found that a strong magnetic field of $35 \mathrm{x}$ $10^{5} \mathrm{~A} / \mathrm{m}$ resulted in a considerable decrease in wear. On the other hand. Kumagai et al $[8,9]$ found that very weak magnetic field also decrease wear. They postulated that the decrease in wear was caused by magnetic-field-promoted oxidation of wear particles. Muju et al $[10,11]$ concluded that the wear rate of materials having low magnetic permeability was reduced on application of a dc external magnetic field but the reason for this had not been clarified. Furthermore, Hiratsuka [12] also reported a reduction in wear of metais under boundary lubrication when a magnetic field was applied between sliding surfaces.

In the present work, an experimental study was conducted to elucidate the role played by a magnetic field, applied between rubbing surfaces, upon the wear rate and variations in counterface surface roughness. A constant magnetic field was applied during sliding of steel on steel and brass on steel. The tests were performed in both dry and oil lubricated sliding conditions. Comparisons between the wear rates and counterface surface roughnesses are presented with and without the presence of magnetic field.

\section{TEST-RIG, MATERIALS AND TEST PROCEDURE}

\section{I- Test-rig}

The experimental work in this paper was conducted on a reciprocating wear testing machine. The machine is driven by a constant A.C. motor of 1 horsepower and 1725 $\mathrm{rpm}$. A voltage regulator is connected to the motor to reduce the input speed of the test-rig to any desired speed value. The drive motor is connected to a crank-shaft through a flexible coupling to compensate for any misalignment. The crankshaft is supported on two sealed deep-groove ball bearings, mounted in two casted split pedestal bearings. On the crankshaft, two connecting-rods are mounted on the crankpins with needle bearings at the big-ends of the connecting-rods. The ratio of the crank length to the connecting-rod length is 1:3.5. The small ends of the connecting-rods are connected to reciprocating pin-holder blocks by means of pins supported on sealed ball-bearings. Two pin-holders are verically freely connected in the pin-holder blocks and these support the applied dead loads at one end while at the other end, the pin tested materials are fixed.

The counterfaces to the pins were two flat metal plates fixed in rectangular grooves forned in two metal blocks which are fastened to the test-rig base. The rectangular grooves allowed 
tests to be conducted either diy or lubricated by oil poured in the recesses. A mechanica counter is fixed to the base near the reciprocating block to connt the number of stroke: performed in each test. For tes!s conducted in the presence of magnelic field, magnets wert attached to the tested reciprocating pins. Fig. I demonstrates a view for the test-rig and it main components.

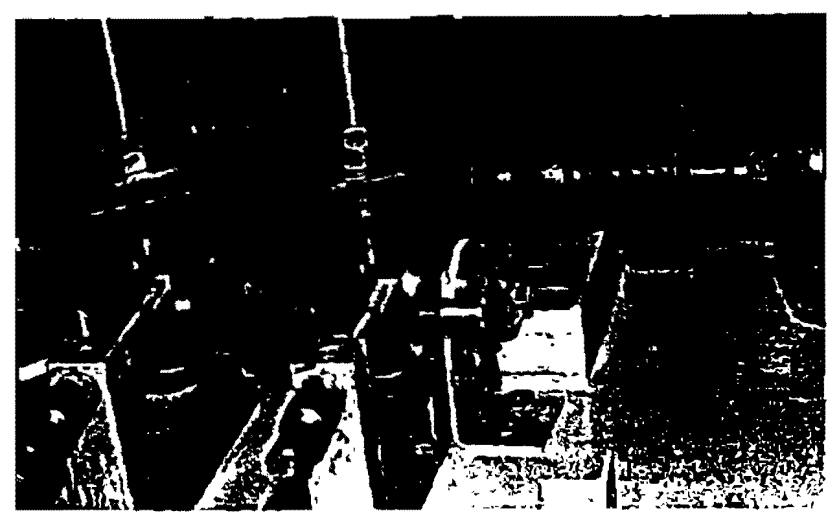

Fig. I View of Test-rig

\section{II- Materials}

The materials tested were commercial steel 302 (hardness $110 \mathrm{BHN}$ ) and 70/30 brass (hardness $48 \mathrm{BHN}$ ). The tested pins were $6 \mathrm{~mm}$ in diameter while the steel counterfaces were $40 \times 80 \times 5 \mathrm{mms}$ in dimensions. The chemical composition and mechanical properties of the tested materials were as illustrated in Table 1.

\section{III- Test Procedure}

The operating conditions which were employed for testing programme were as given in Table 3. The test surfaces of the steel plates were machined and ground to surface roughnesses in the range $0.05-0.13 \mathrm{um} \mathrm{Ra}$. The surface roughnesses were measured before and after testing using a Taylor-Hobson Talysurf profilometer. Measurements were taken parallel and normal to sliding direction within the wear tracks. The roughness values quoted in this work are mean values of five traversals in each direction arbitrarily chosen. Before dry resting, the rubbing surfaces were chemically and mechanically cleaned using acetone and ultrasonic cleaning devise to remove any traces of grease, dust or contaminants. Wear rates were calculated from weight losses recorded after predetermined sliding distances. The tesis were internpted periodically to allow the pins to be weighed using sensitive digital balance of accuracy $10 \mathrm{~g}$. Weight losses were converted to equivalent volumes by dividing them by the density of the material. The wear rate was then calculated from the formula:

$$
\text { Wear rate }=\frac{\text { Volume loss per meter of sliding }}{\text { Applied load }}\left(\mathrm{mm}^{3} / \mathrm{N} . \mathrm{m}\right)
$$


To give an insight on the dominant wear mechanism, a magnified examination of the wear tracks was performed using microscope of magnification 40 and $40^{\circ}$. Photographic views were taken and explanations for the dominant wear process are given.

Table 1. Composition and Mechanical Properties of Tested Materials

\begin{tabular}{|l|c|c|c|c|}
\hline Materinl & Chemical Composition & \multicolumn{3}{|c|}{ Mechanical Properties } \\
\cline { 3 - 5 } & & $\sigma_{y}(\mathrm{MPa})$ & E iGPa) & $\mathrm{BHA}$ \\
\hline Brass $70 / 30$ & $70 \% \mathrm{Cu}, 0.75 \% \mathrm{Sn}, 1.5 \% \mathrm{~Pb}, \mathrm{Zn}(\mathrm{rest})$ & 400 & 105 & 48 \\
\hline Steel 302 & $0.2 \% \mathrm{C}, 0.9 \% \mathrm{Mn}, 0.04 \% \mathrm{P}, 0.15 \% \mathrm{Si}$ & 300 & 207 & 110 \\
\hline
\end{tabular}

Table 2. Experinental Test Conditions

\begin{tabular}{|l|l|}
\hline Parameter & Condition \\
\hline Type of motion & Reciprocating \\
Type of contact & Pin-on-flat \\
Pin stroke & $7 \mathrm{~cm}$ \\
Average speed & $950 \mathrm{rpm}$ \\
Test conditions & Dry and oily \\
Normal load & 5 and $10 \mathrm{~N}$ \\
Contact pressure & 17.7 or $35.4 \mathrm{~N} / \mathrm{cm}^{2}$ \\
Ambient conditions & $30^{\circ} \mathrm{c}$ and $60 \% \mathrm{Humidity}$ \\
Test intervals & $5000 \mathrm{strokes}$ \\
Initial roughness & $0.05-0.13 \mu \mathrm{m} \mathrm{Ra}$ \\
\hline
\end{tabular}

\section{TEST RESULTS}

\section{I- Wear of Steel Against Steel}

\section{A) Under Dry Sliding Conditions}

Fig. 2 displays the variations of wear rate with sliding distance of steel pins reciprocating against steel counterfaces under applied loads of 5 and $10 \mathrm{~N}$ in dry sliding conditions. As can be seen, in the absence of magnetic field, the wear rates at both 5 and $10 \mathrm{~N}$ loads increase linearly with increasing sliding distance, being higher in values for the $10 \mathrm{~N}$ load. On the other hand, when the magnetic field was applied, the wear rates exhibit a linear decrease with the increase in sliding distance, either at $5 \mathrm{~N}$ or $10 \mathrm{~N}$ load. The tested lighter load (5 M) displays a significant reduction in wear rates with progressive sliding distances. In dry sliding tests, the wear rates are of $10^{3}$ order of magnitude.

B) Under Oil Lubricated Sliding Conditions

Fig. 3 demonstrates the relationships between the wear rates and sliding distances for steel on steel in lubricated sliding under loads of $S \mathrm{~N}$ and $10 \mathrm{~N}$. In the absence of magnetic field, the presence of lubricant plays the major role in reducing the wear rates with progressive sliding distance, as shown for the 5 and $10 \mathrm{~N}$ loads. The later load obviously exhibits higher 


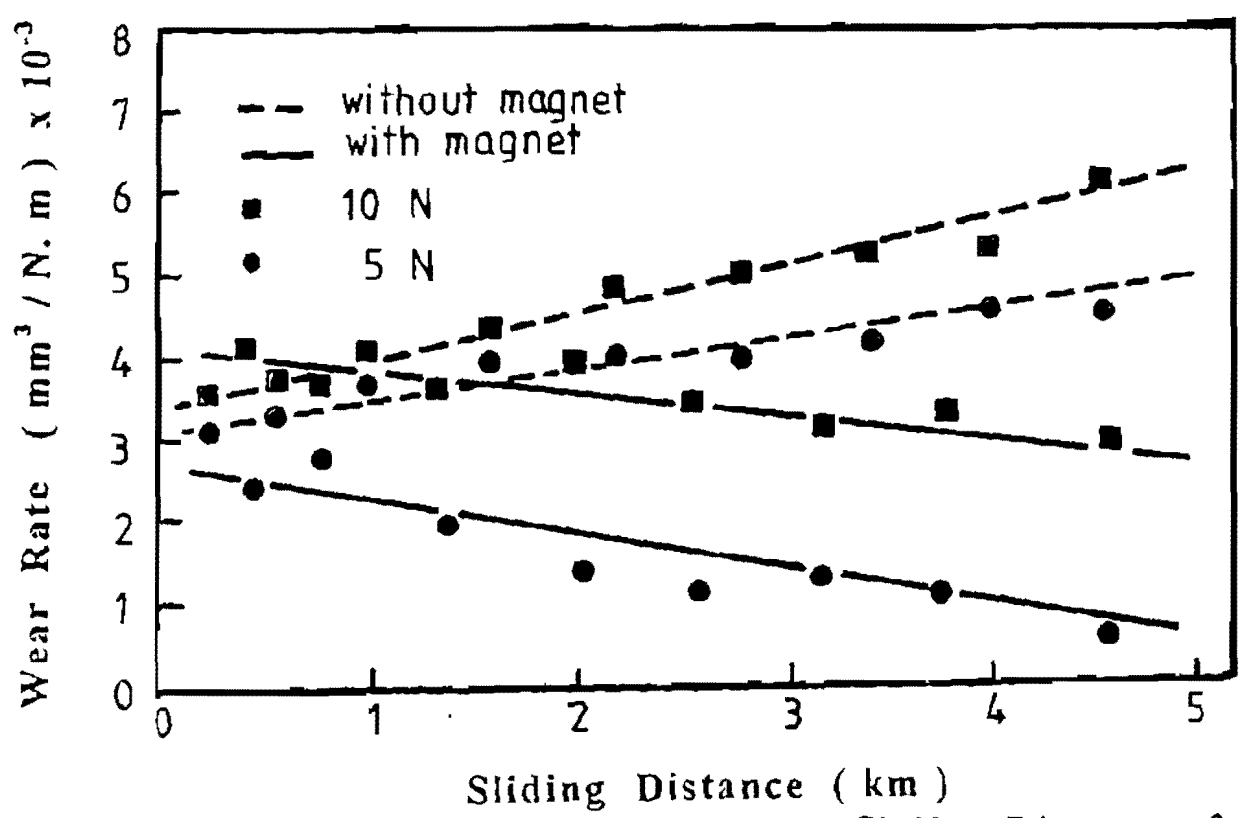

Fig. 2 Variation of Wear Rate with Sliding Distance for Steel on Steel under Dry Sliding Conditions.

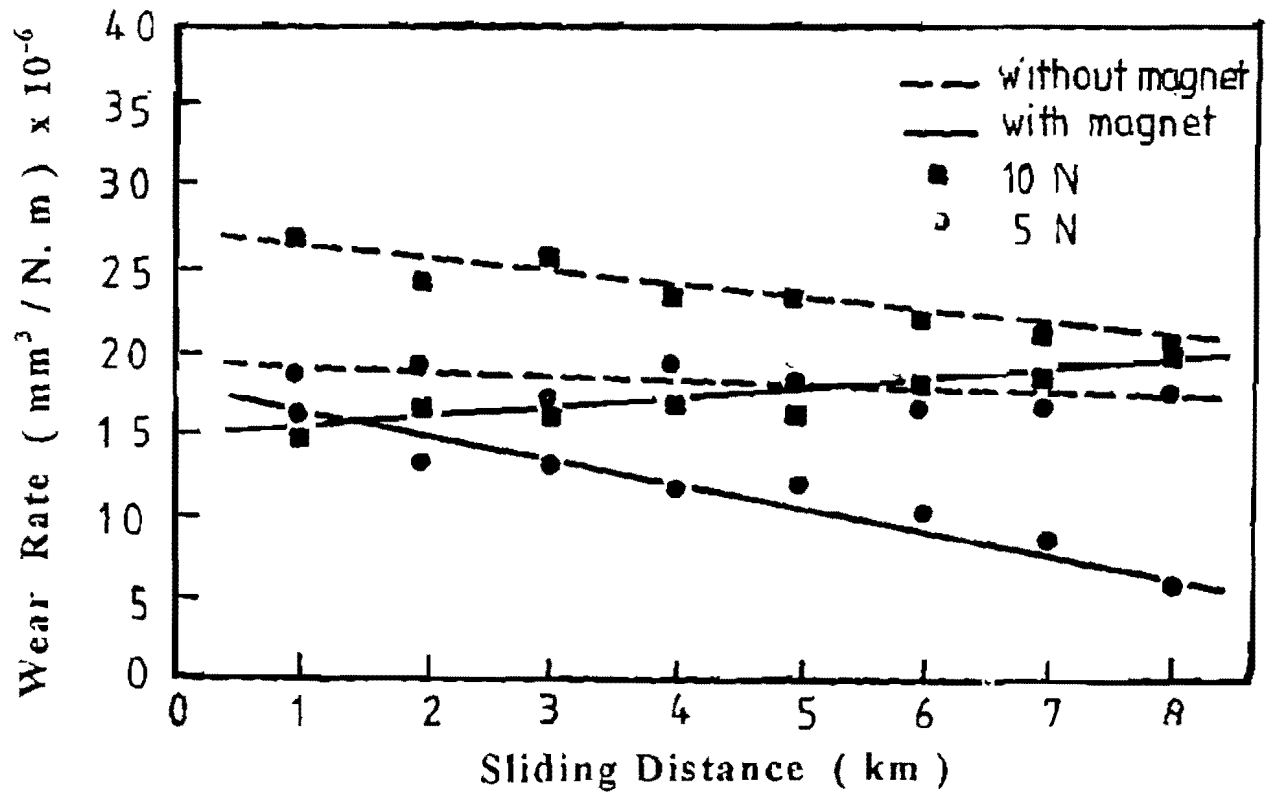

Fig. 3 Variation of Wear Rate with Sliding Distance for Steel on Steel under Lubricated Conditions. 
M. 6 M. Zaki

wear rate values compared with the $5 \mathrm{~N}$ load. Although the application of magnetic field between the rubbing surfaces results in lower wear rates at both investigated loads, compared with those obtained in the absence of magnetic field, but, as can be seen, the wear rates, for $10 \mathrm{~N}$ load, with the presence of magretic field, increase with continuous slidiag. On the contrary, the applied magnetic field resulted in large progressive reduction in wear rates with increasing sliding distance for the lower tested load $(5 \mathrm{~N})$. The wear rates in lubricated sliding are of $10^{6}$ order of magnitude which demonstrates the high beneficial effect of lubricant upon reducing wear when compared with dry sliding conditions.

\section{II- Wear of Brass Against Steel}

A) Under Dry Sliding Conditions

The variations of wear rates with sliding distances, for brass pins sliding against steel counterfaces, under -dfy sliding conditions, are shown in Fig. 4 . The results indicate that aprogressive reduction in the wear rates occurres with increasing sliding distances for the 5 $\mathrm{N}$ load while the $10 \mathrm{~N}$ load exhibit slight increase in wear rates with continuous sliding in the absence of the magnetic field. As in previous results, for steel on steel, the application of the magnetic field results in lower wear rates compared with those obtained in the absence of magnetic field at both tested loads. It is worth noting that in the presence of magnetic field, the $10 \mathrm{~N}$ load results in a linear increase in the wear rates with increasing sliding distance. However, the $5 \mathrm{~N}$ load exhibits a continuous linear decrease in the wear rate values with increasing sliding distance.

B) Under Oil Lubricated Sliding Conditions

Fig. 5 illustrates the resulted relationships between the wear rate and sliding distance for brass against steel under oil lubricated sliding conditions. As can be seen, all wear rate plots, either at $5 \mathrm{~N}$ or $10 \mathrm{~N}$ load and with the absence or presence of the magnetic field, decrease exponentially with increasing sliding distance. Similar to previous results, the presence of the magnetic field results in lower wear rate values then those obtained at similar sliding conditions without the magnetic field. The $5 \mathrm{~N}$ load, with the presence of magnetic field, exhibits the lowest values of wear rates against sliding distances.

\section{DI- Counterfice Surface Roughness Varintious}

Fig. 6 represents bar graphs for the variations of steel counterface surface roughness values for steel on steel and brass on steel under the different testing conditions. As expected, the deterioration in surface roughness is always higher with the utilization of the higher load tested (10 N) compared to that of $(5 \mathrm{~N})$. Furthemore, the presence of lubricant reduces to large extend the variation of surface roughness relative to the initial surface roughness. It is interesting to observe that the presence of the magnetic field has a highly beneficial effect upon reducing the increase in surface roughness to about $50 \%$ of the values obtained at similar testing conditions in the absence of the magnetic field. Such reduction in surface roughness due to the magnetic field presence is more enhanced for steel on steel than for brass on steel. The main reason for that reduction is the attraction of wear debris to the magnet attached to the pin due to the magnetization of the debris. This phenomena is shown in Fig. 7. This eventually reduces the possibility of three body abrasion during sliding and results in decreasing wear rates and limited increase in surface roughness. 
Mansoura Engineering Journal (MEJ), Vol.20,No.2,June 1995

沙. 7

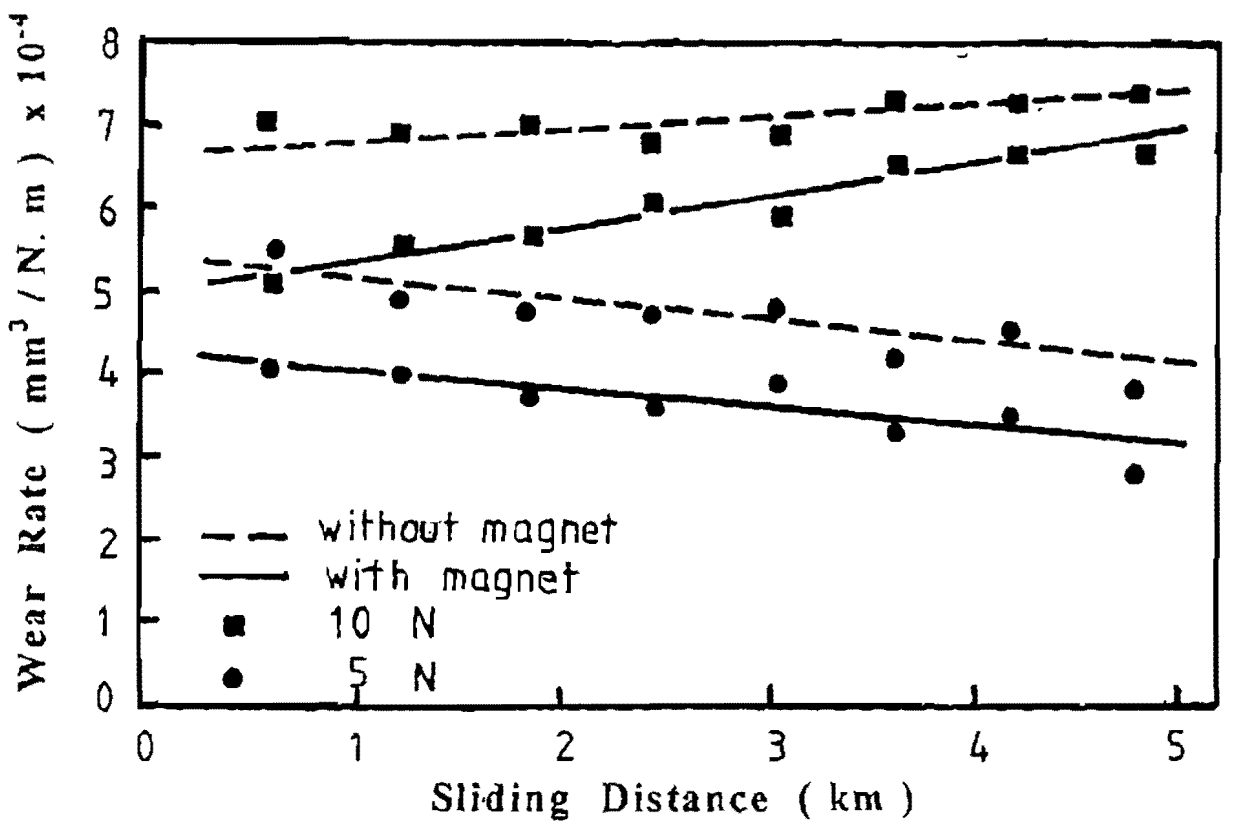

Fig. 4 Variation of Wear Rate with Sliding Distance for Brass on Brass under Dry Sliding Conditions.

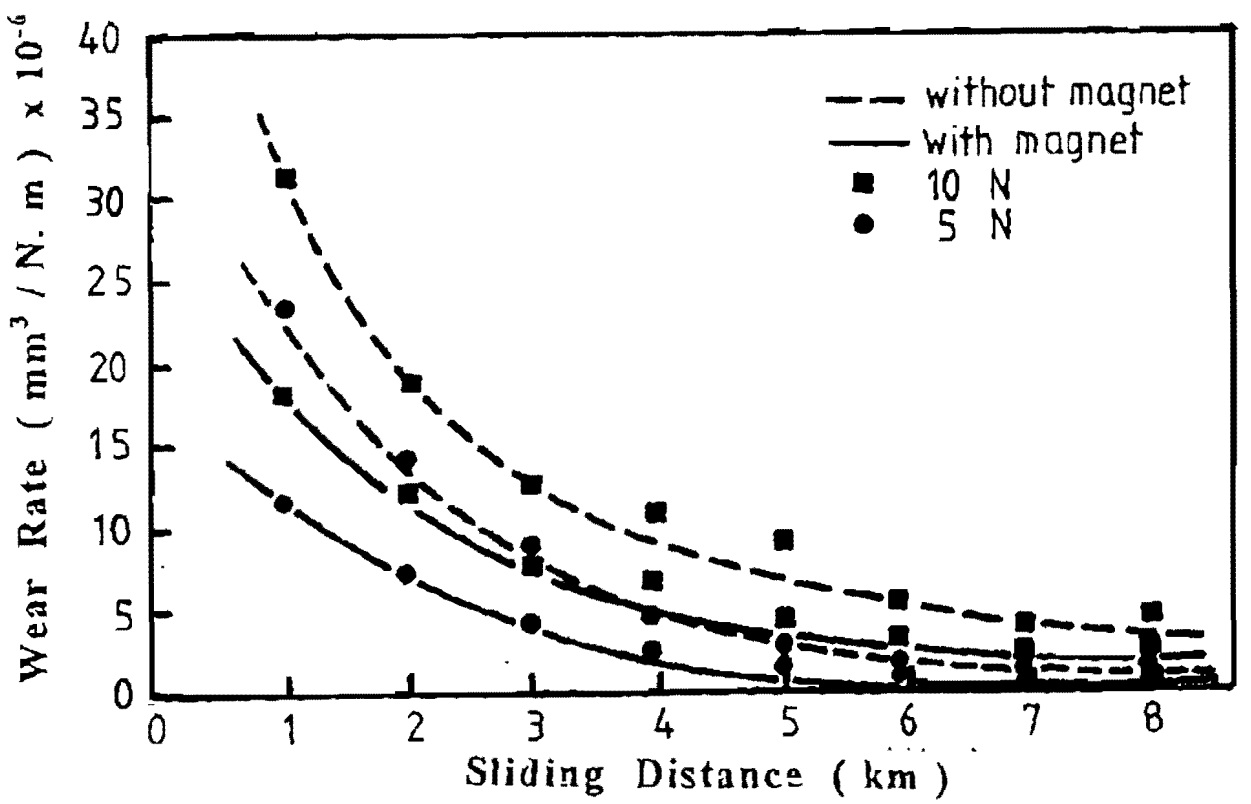

Fig. 5 Variation of Wear Rate with Sliding Distance for Brass on Brass under Lubricated Conditions. 
M. 8

M. Zaki
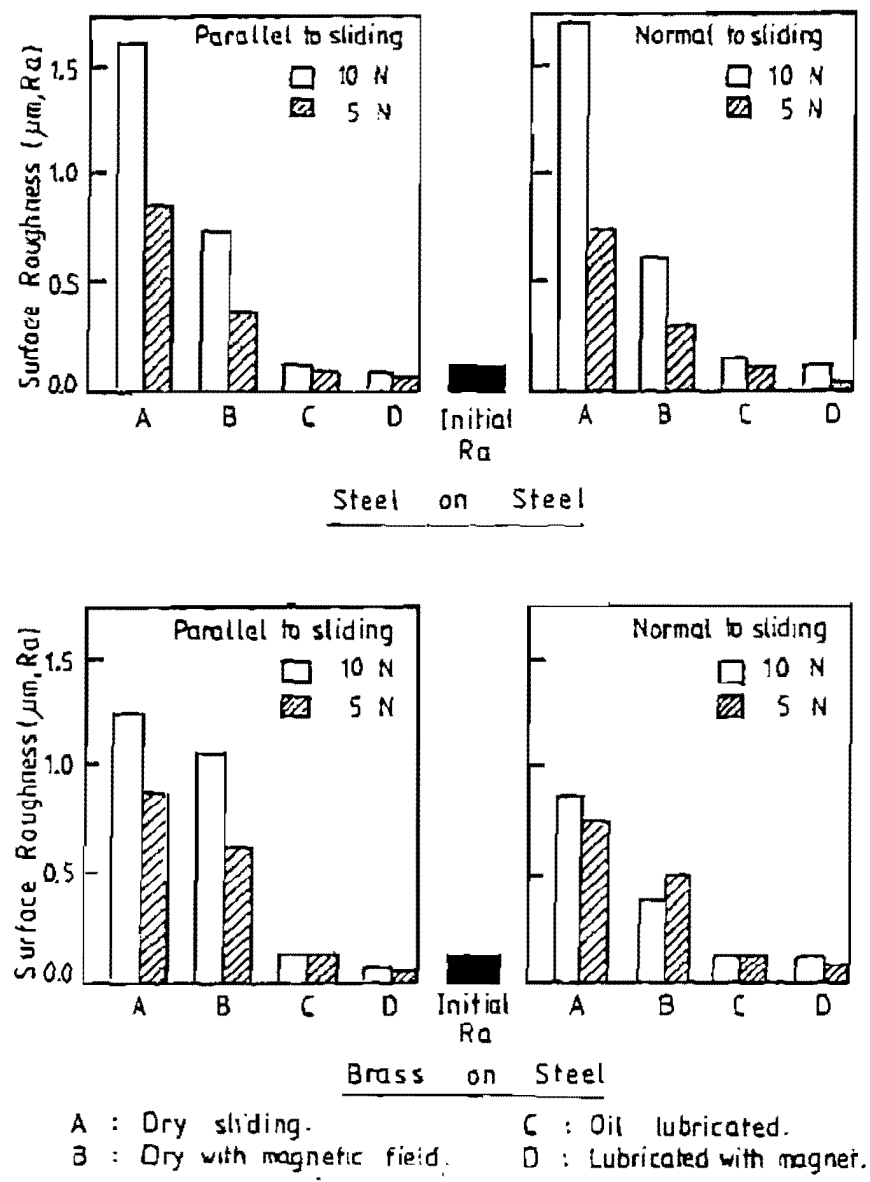

Fig. 6. Surface Roughness Variations for steel counterfaces Relative to Initial Roughness.

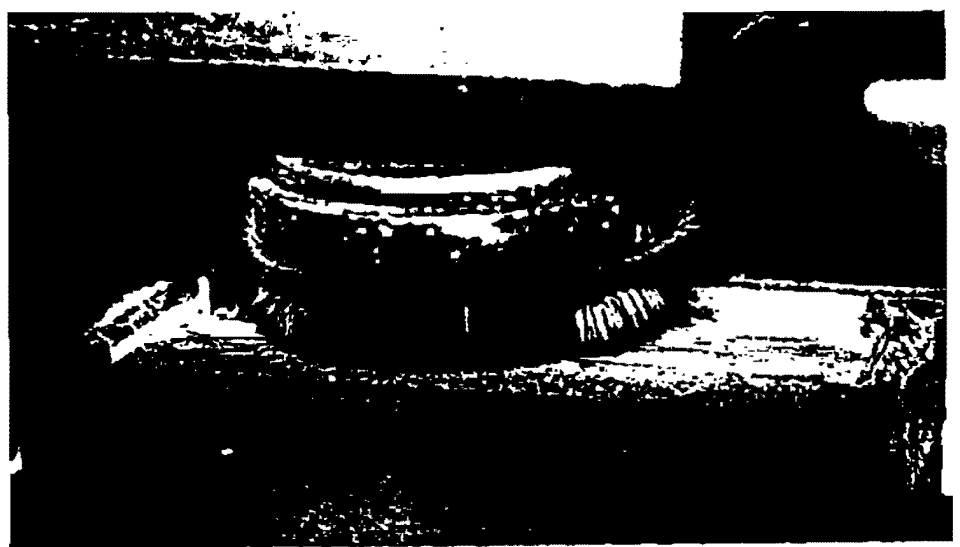

Fig. 7. Attracted Wear Particles to the Pin and Magnet 
It is worth noting that in the presence of both lubricant and magneric field, the surface roughness values at the termination of tests were even lower than the initial surface roughness in particular with the lower tested load $\left(\begin{array}{ll}5 & \mathrm{~N}\end{array}\right)$. The variations of surface roughness within the sliding tracks, in the parallel and normal directions to sliding, exhibit similar trends.

\section{VI- Optical Examination of Wear Tracks}

\section{A) Wear Tracks For Stecl Against Stecl}

Optical examination of the wear tracks produced from tests of dry sliding of steel on steel has revealed that there is a large deterioration in surface roughnesses. Transfer of steel to the counterface takes the form of loose and adhering particles which soften due to the large friction heating resulted. These softened dispatched and dispersed particles quickly cooled when subjected to air forming rough surfaces. Some of these particles were pushed away to the edge of the wear track as shown in Fig. 8. However, in the iniddle of the wear track, due to lack of heat dissipation, the surface layer was completely molten as shown in Fig. 9. Meanwhile, due to repeated sliding on the same track, some of the hardened transferred particles were subject to farigue and cracks were forming within the matrix of these particles. Evidence of such fatigue and crack initiation and propagation is shown in Fig. 10.

In the presence of the magnetic field in dry sliding, the metal transfer was much less due to the attraction of loose particles to the magnet. Therefore, less tendency to high and large molten debris was encountered. The transfer took the form of disperse paricles of small volume adhering to the counterface as shown in Fig. 11.

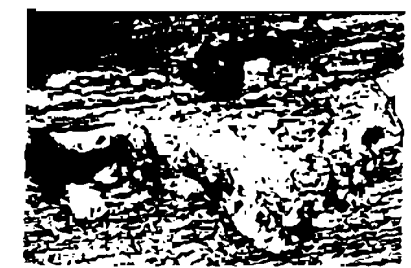

Fig. 8. Steel fragment pushcd out from the wear track.

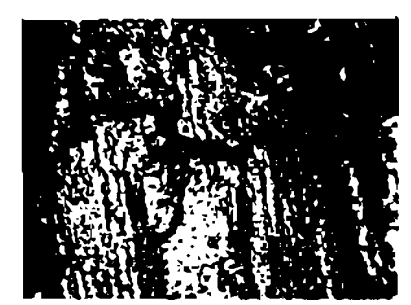

Fig. 10. Crack formation due to the fatigue wear.

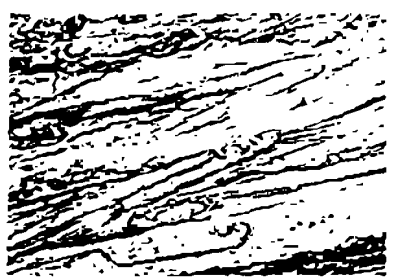

Fig. 9. Molten layer of steel at middle of track.

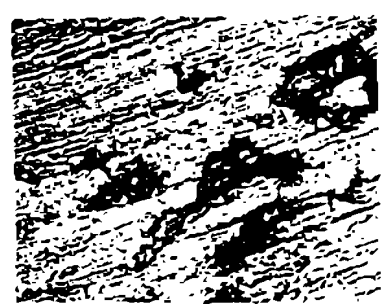

Fig. 11. Wear track in the presence of magnet.

For lubricated tests, there was almost no change in the surface roughness of the counterfaces before and after tesing. Only very small detached particles adhered to the counterface as shown in Fig. 12. On the other hand, for lubricated tests with the presence of magnetic fieid, the resulting wear track was very smooth with fine abrasion lines in the sliding direction as shown in Fig. 13. 
M. 10 M. Zaki

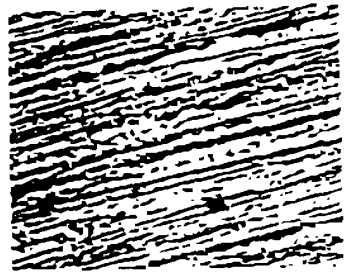

Fig. 12. Mininum transfer in steel lubricated tests.

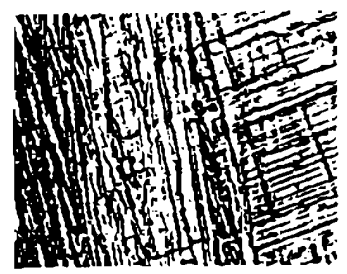

Fig. 13. Smooth wear track in lubricated test with magnetic field.

\section{B) Wear Tracks For Brass Against Steel}

In the dry sliding of brass/steel combination, there was a transfer from brass to the steel counterface. Adhesion plays an important role in the wear process. There was a softening process at the brass surface which facilitated brass transfer. Generally, transfer occured in the form of particles and with repeated sliding these particles flattened on the steel surface while some particles jumped outside the wear track as shown in Fig. 14. Another important wear mechanism also took place during repeated sliding which is fatigue wear. This fatigue wear mechanism is manifested in Fig. 15. This indicates that cracks initiate beneath the surface, at weak points, then propagate to the surface resulting in surface area removal in weak spots.

When surfaces were lubricated, transfer was minimum and took the form of descrete parts on the steel surface as shown in Fig. 16. However, in the presence of the magnetic field, the counterfaces remained smooth with slight improvement in surface roughness value relative to the initial surface roughness. Fig. 17 demonstrates the wear track in the presence of lubricant and magnetic field.

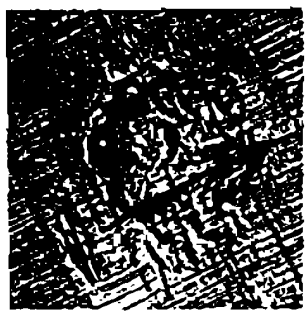

Fig. 14. Brass fragnent outside the wear track.

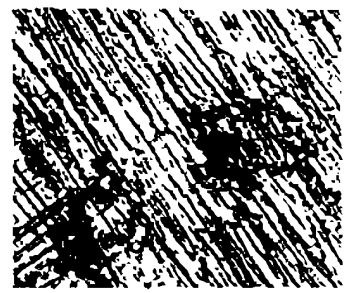

Fig. 16. Wear track for brass lubricated test.

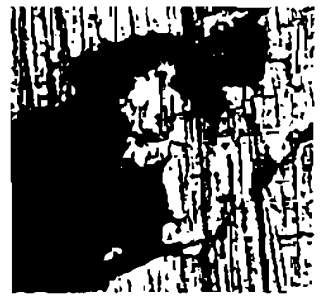

Fig. 15. Evidence of fatigue wear process.

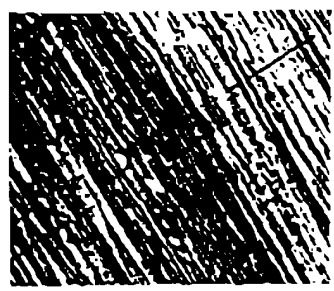

Fig. 17. Wenr track with lubrication and magnet. 
Mansoura Engineering Journal (MEJ), Vol.20,No2,June 1995 M.11

\section{DISCUSSION OF RESULTS}

The present experinental investigation has revealed that the presence of a magnetic field, between rubbing surfaces, has a remarkable effect upon the wear rate and surface roughness variations. For steel or brass pins, reciprocating against steel counterfaces, under 5 or $10 \mathrm{~N}$ load, the magnetic field results in lower wear rates and improving surface roughnesses compared to similar tests performed without magnetic field. Some investigators $[7,9]$ speculated that the only dominant reason for wear rates reduction, under dry sliding of metals, is the oxidational promoting effect occurring to metals in the presence of magnetic fields. They noted that this accelerated oxidacion disturbs the mutual transfer and growth and results in finer wear paricles. Accordingly, the wear decreasing effect of the magnetic field is caused by the fine wear paricles formed by promoted oxidation and then attached to the wear surfaces due to magnetization forces. The present results are in agreement with previous works in that the presence of magnetic field reduces the wear rates of metals. However, our reasons for such wear rate reduction contradict with those proposed by previous mentioned investigators. The present work has clarified that, in dry sliding of steel on steel, the metal transfer in the presence of magnetic field, was much reduced. It is proposed that two main reasons are responsible for wear rate reduction and improvement in counterface surface roughness under magnetic field. The first is the change of contact mechanism from three-body abrasion (metal/transfer/metal) to mainly two-body abrasion (metal/metal) due to the attraction of loose wear particles to the magnet during sliding. The second reason is the mutual repulsion of sliding surfaces as the pin and counterface acquire the same sign of charge in the presence of the magnetic field. This repulsion is enhanced under lighter normal load tested. Evidence of such repulsion is observed in Fig. 2 . where the reduction of wear rates, under the lighter load, is much higher then that under the heavier tested load. It is worth noting that there was no sign of wear particles oxidation, which was proposed by other investigators, as the wear particles did not grow darker in colour which would suggest that oxidation is promoted by the magnetic field.

Similar behaviours for the wear rates and counterface surface roughnesses in the presence of magnetic freld are manifested in lubricated tests. The wear rates abtained in the presence of magnetic field were lower in values than those for tests performed under similar conditions without magnetic field. The proposed oxidation effect, put forward by previous workers, is not also valid for the lubricated sliding reduction in wear due to the presence of oil which contains anti-oxidant additives, thus preventing the oxidation of contact surfaces and wear particles. For lubricated tests, it is suggested that magnetohydrodynamic lubrication will be in action in the presence of magnetic field. This type of lubrication will generate lifting pressure capable of decreasing the real area of contact between the sliding surfaces, thus reducing wear rates to minimum values in particular under light load. The results obtained in lubricated sliding support such suggestion as the wear rates under 5 $N$ load decreased linearly to about $75 \%$ of their initial wear rate value within the duration of test. The counterface surface roughnesses at the termination of lubricated tests were almest similar in values to the initial surface roughness.

For brass sliding on steel, either dry or lubricated, the influence of magnetic field upon wear rates has a similar trend to that of steel on steel. The wear rates in magnetic field were lower in values than those obtained for similar tests with no magnetic field. However, the lubricant plays a major role in reducing wear rates when comparing dry and lubricated wear 
values. While for steel on steel the dominant wear mechanisms during sliding were abrasive and fatigue, but for brass on steel adhesive and fatigue wear mechanisms were more enhanced. In lubricated sliding for brass on steel there was no significant changes in the counterface surface roughnesses compared to the initial roughness. Again, the mutual repulsive forces in dry sliding and the magnetohydrodynamic lubrication in lubricated sliding were the two main mechanisms responsible for the reduction in wear rates and the limited increase in surface roughnesses.

\section{CONCLUSIONS}

From the obtained results, the foilowing conclusions can be deduce:

1. The presence of magnetic field between rubbing surfaces, in the early stages of sliding, decreases the wear rates of steel/steel and brass/steel combinations either under dry of lubricated sliding conditions. The influence of magnetic field is more enhanced under light load and relatively small sliding distance. However, severe wear rates may be expected at longer sliding distance due to premature fatigue effects.

2. The wear decreasing effect of the magnetic field, in dry sliding of steel against steel, is caused by the change of contact from three-body to two-body abrasion mechanism and the reduction of real contact area due to repulsive forces.

3. The main dominant wear mechanisms for dry sliding of steel on steel are abrasive and fatigue.

4. Magnetohydrodynamic lubrication reduces wear rates and improves surface roughness in lubricated sliding of metals in the presence of a magnetic field.

5. For brass sliding against steel, adhesive and fatigue wear mechanisms are dominant under reciprocating dry sliding conditions.

6. The influence of magnetic field in reducing wear rate and improving surface roughness is more remarkable for steel on steel than for brass on steel due to the easily magnetization of steel.

\section{REFERENCES}

1. Postnikov, S.N. "Electrophysical and Electrochemical Phenomena in Friction, Cutting and Lubrication". Litton Educational Publishing Inc., New York (1978).

2. Goldblatt, I.L. "Self-generated Voltages under Boundary Lubricated Conditions". In: Fundamental of Tribology, Edited by Such, N.P. and Saka, N..The MIT Press, Cambridge, Mass. (1980), 981-1005.

3. Roberts, A.D. "Direct Measurement of Electrical Double-layer Forces between Solid Surfaces". Journal of Colloid and Interface Science, Vol. 41, No. I, (1972), 23-34.

4. Kelly, E.J. "Magnetic Field Effects on Electrochemical Reactions Occurring at Metal/Flowing-Electrolyte Interfaces". Journal of Electrochemical Society, Vol. 124, No. 7. (1977), 987-999.

5. Haberman, H.and Liard, G. "An Active Magnetic Bearing System". Tribology International, Vol. 13, No. 2, (1980), 85-89. 
Mansoura Engineering Journa! (MEJ), Vol.20, No.2, June 1995 M.13

6. Yngve, N. and Martin, W.K. "The Influence of Electrochemical Potential on Wear". Wear, Vol. 104, No. 2. (1985), 139-150.

7. Hiratsuka, K., Sasada, T. and Norose, S. "The Magnetic Effect on the Wear of Materials". Wear, Vol. 110, (1986), 251-261.

8. Kumagai, K. "Effects of Magnetic Field on Wear of Ferromagnetic Materials". Bull. JSPE, Vol. 19, No. I. (1985), 43-48.

9. Kumagai, K., Takahashi, M. and Kamiya, 0 . "Wear Behaviour in the Presence of Magnetic Fields for Pin-on-disc Repeated Dry Wear Tests". Tribology International, Vol. 25, No. 2, (1992), 9]-98.

10. Muju, M.K. and Ghosh, A. "A Model of Adhesive Wear in the presence of a Magnetic Field". Wear, Vol. 41, No. 1, (1977), 103-116.

11. Muju, M.K and Radhakrishma, A. "Wear of Non-magnetic Materials in the Presence of a Magnetic Field". Wear, Vol. 58, No. 1, (1980), 49-58.

12. Hiratsuka, k. "Wear of Metals in a Magnetic Field in a Boundary Lubrication ". Proceeding of the 19th Leeds-Lyon Symposium on Tribology (Thin Films in Tribology) Vol. 5, No. 3, (1992). 